\title{
A Double Inverted F-Shape Patch Antenna for Dual-Band Operation
}

\author{
M. M. Islam, ${ }^{1}$ M. R. I. Faruque, ${ }^{1}$ W. Hueyshin, ${ }^{1}$ J. S. Mandeep, ${ }^{2}$ and T. Islam ${ }^{2}$ \\ ${ }^{1}$ Centre for Space Science (ANGKASA), Universiti Kebangsaan Malaysia, 43600 Bangi, Selangor, Malaysia \\ ${ }^{2}$ Department of Electrical, Electronic and Systems Engineering, Universiti Kebangsaan Malaysia, 43600 Bangi, Selangor, Malaysia \\ Correspondence should be addressed to M. M. Islam; mmoiislam@yahoo.com
}

Received 25 October 2013; Accepted 17 November 2013; Published 27 April 2014

Academic Editor: Rezaul Azim

Copyright (c) 2014 M. M. Islam et al. This is an open access article distributed under the Creative Commons Attribution License, which permits unrestricted use, distribution, and reproduction in any medium, provided the original work is properly cited.

\begin{abstract}
A double inverted F-shape patch antenna is presented for dual-band operation. The proposed antenna is comprised of circular and rectangular slots on a printed circuit board of $40 \mathrm{~mm} \times 40 \mathrm{~mm} \times 1.6 \mathrm{~mm}$ with a $50 \Omega$ microstrip transmission line. Commercially available high frequency structural simulator (HFSS) based on the finite element method (FEM) has been adopted in this investigation. It has a measured impedance bandwidths ( $2: 1 \mathrm{VSWR})$ of $18.53 \%$ on the lower band and $7.8 \%$ on the upper band, respectively. It has achieved stable radiation efficiencies of $79.76 \%$ and $80.36 \%$ with average gains of $7.82 \mathrm{dBi}$ and $5.66 \mathrm{dBi}$ in the operating frequency bands. Moreover, numerical simulations have been indicated as an important uniformity with measured results.
\end{abstract}

\section{Introduction}

The raising demands of wireless communication systems enforce the improvement of dual-band antennas that have abilities to operate under different standards in different frequency bands. Advances in wireless communications have introduced tremendous demands in the antenna technology. It also paved the way for wide usage of mobile phones in modern society resulting in mounting concerns surrounding its harmful radiation $[1,2]$. Microstrip patch antenna plays an important role as a harbinger in wireless communication systems and is gradually carrying out to face the changing demands of update antenna technology. Microstrip patch antennas are presently under concern for using in broadband communication systems due to their attractive characteristics, such as low profile, low cost, lightweight, wide frequency bandwidth, ease of fabrication, and easy integration with monolithic microwave integrated circuits $[3,4]$. However, the limitations of the microstrip patch antennas are having narrow bandwidth, and for that reason the demand of the bandwidth enhancement is gradually rising in the practical applications [5]. In order to enhance its bandwidth, many approaches have been applied conventionally, such as using thick substrates with low dielectrics constant, impedance matching network, parasitic patches stacked on the top of the main patch [6], slots loaded on the patch, high dielectric constant substrate, and adopting short-circuit pin [7].

In [8], a rectangular slot antenna has been stated for dual frequency operation. Reference [9] has narrated a printed dipole antenna to cover dual band with U-slot arms. Reference [10] has been reported a low cost microstrip dipole antenna for wireless communications. In [11], a PIFA antenna has been presented for dual band operation with U-slot. Reference [12] has been mentioned a dual loop antenna for $2.4 / 5 \mathrm{GHz}$ wireless LAN. A monopole antenna with double$\mathrm{T}$ has been stated in [13] for $2.4 / 5.2 \mathrm{GHz}$ WLAN operations. A dual polarized antenna has been mentioned in [14] for Ku-band application. Microstrip antennas on FR4 substrate material were discussed for UWB applications in $[15,16]$.

In this research, a double inverted F-shape $40 \times 40 \mathrm{~mm}^{2}$ patch antenna for dual-band operation has been proposed and investigated to increase the bandwidth and reduce the size at the same time. The effect on antenna resonances and other antenna parameters is concentrated due to slots on the patch and ground plane to design the proposed dual-band double inverted F-shape antenna with enhanced bandwidth and efficiency. Some techniques are employed such as increasing substrate thickness, changing patch by cutting rectangular slots, and cutting ground plane to achieve the resultant parameters such as impedance matching, gain, 


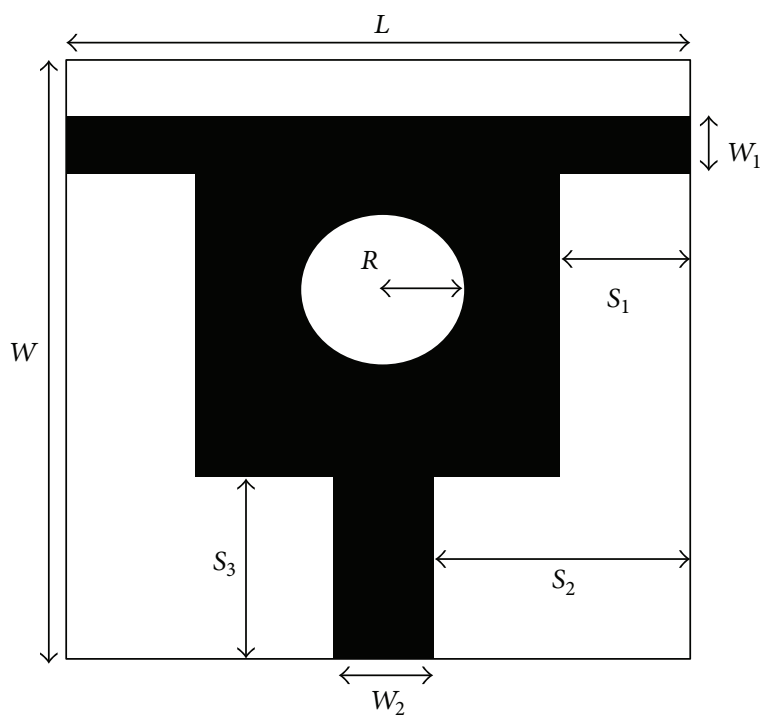

(a)

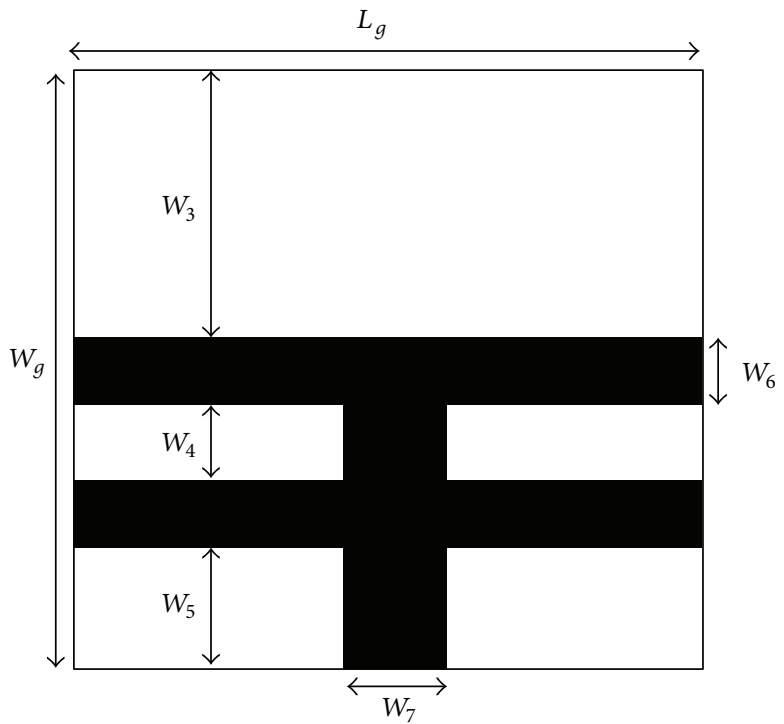

(b)

Figure 1: The proposed antenna (a) top view and (b) Bottom view.

radiation pattern, and return loss. The results have been given a hint that the proposed antenna is appropriate for X-band and $\mathrm{Ku}$-band applications.

\section{Antenna Geometry and Optimization}

The length and width of the patch antenna can be calculated from (1) narrated in [17]. While $L$ and $W$ are the length and width of the patch, $c$ is the velocity of light, $\varepsilon_{r}$ is the dielectric constant of substrate, $f_{0}$ is the target center frequency, and $\varepsilon_{e}$ is the effective dielectric constant. Consider

$$
\begin{aligned}
W & =\frac{c}{2 f_{0}} \sqrt{\frac{\varepsilon \varepsilon_{r}+1}{2}}, \\
L & =\frac{c}{2 f_{0} \sqrt{\varepsilon_{r}}}-2 \Delta l .
\end{aligned}
$$

The geometry of the proposed antenna is as shown in Figure 1. The antenna consists of rectangular conducting slots on patch and two on the ground. The design procedure begins with the radiating patch with substrate, ground plane, and a feed line. It has been printed on a FR4 substrate with $1.6 \mathrm{~mm}$ thickness that contains relative permittivity 4.60 , relative permeability 1 , and dielectric loss tangent 0.02 . A rectangular slot is cut from one side of the copper patch to another. Another two rectangular slots are also cut from the middle of the patch. Five lateral rectangular slots are also cut from the ground plane.

Thus, the proposed double inverted F-shape microstrip patch antenna is achieved. Two resonant frequencies, $11.32 \mathrm{GHz}$ and $14.96 \mathrm{GHz}$, are obtained adjusting length, width, and slots of the proposed antenna endlessly. Here, microstrip line is used to provide feeding to the proposed antenna.

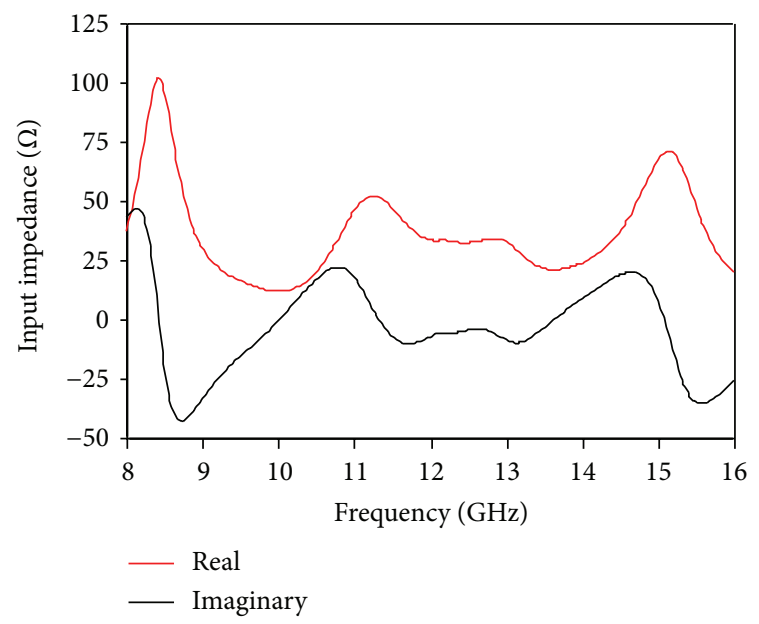

FIGURE 2: Input impedance of the proposed antenna.

The subminiature version A (SMA) connector that contains $50 \Omega$ is conducted at the end of antenna feeding line for input RF signal. The input impedance of the proposed antenna is as shown in Figure 2. Finally the optimal dimensions have been determined as follows: $L=40 \mathrm{~mm}, W=$ $40 \mathrm{~mm}, R=6 \mathrm{~mm}, S_{1}=10 \mathrm{~mm}, S_{2}=16.5 \mathrm{~mm}, S_{3}=$ $12 \mathrm{~mm}, W_{1}=4 \mathrm{~mm}, W_{2}=7 \mathrm{~mm}, L_{g}=40 \mathrm{~mm}, W_{g}=40$, $W_{3}=18 \mathrm{~mm}, W_{4}=6 \mathrm{~mm}, W_{5}=8 \mathrm{~mm}, W_{6}=4 \mathrm{~mm}$, and $W_{7}=7 \mathrm{~mm}$. The proposed prototype of the antenna is shown in Figure 3.

The return loss of simulation with different substrate materials is demonstrated in Figure 4. Teflon is a fluorine plastic that is very slippery with physical properties. It is a brand for polytetrafluoroethylene (PTFE). When we used Teflon (tm) as a substrate material, there was no resonance 


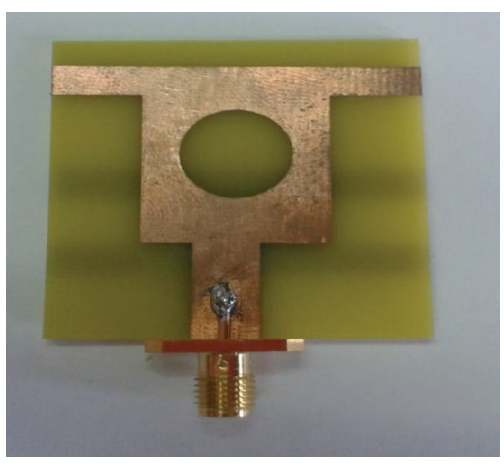

Microstrip patch

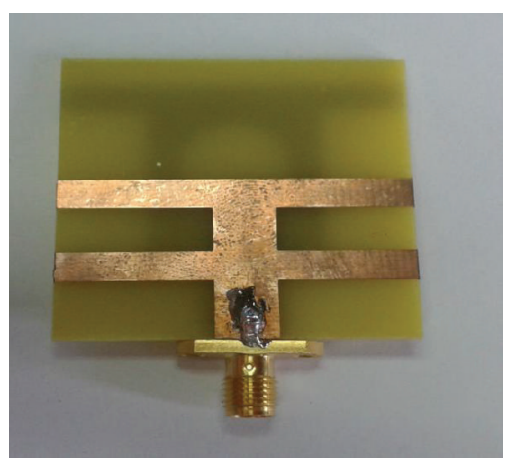

Ground

FIGURE 3: Prototype of the proposed antenna.

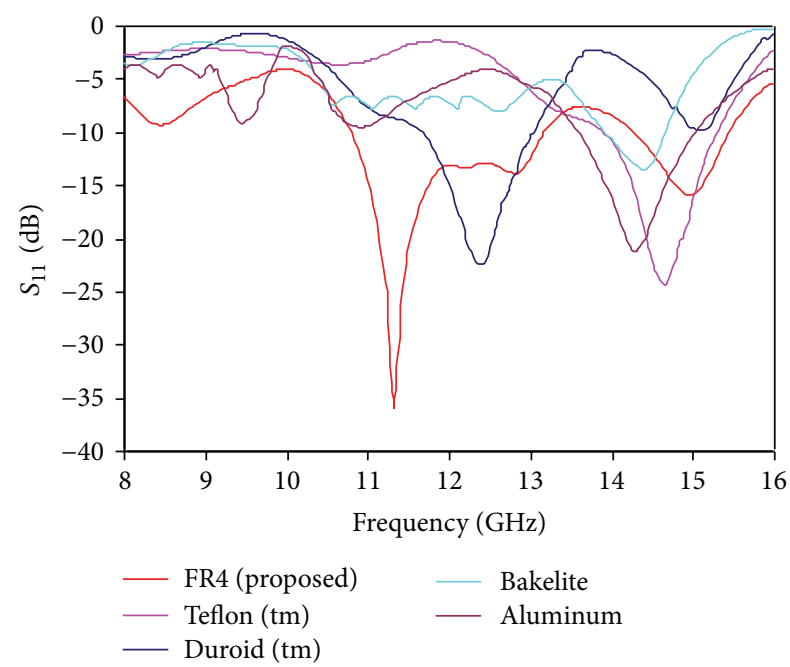

Figure 4: Comparisons of simulated return loss with different materials.

on the lower band. But, resonance was found at $14.68 \mathrm{GHz}$ center frequency on the upper band where $-10 \mathrm{~dB}$ bandwidth is $1.36 \mathrm{GHz}$.

Duroid (tm) is a circuit material with high frequency that is filled with PTFE composite. There are many benefits of Duroid (tm) substrate material such as low outgassing for space applications, low moisture absorption, and low electrical loss. This material is extensively used in space satellite transceivers, radar systems based on ground and airborne, missile guidance systems, and military radar systems. When we used Duroid (tm) as a substrate material, there was no resonance on the upper band. But, resonance was found at 12.40 GHz center frequency on the lower band where $-10 \mathrm{~dB}$ bandwidth is $1.36 \mathrm{GHz}$.

Bakelite is one type of plastic that is a thermosetting phenol formaldehyde resin. It is made from synthetic components achieved from an elimination reaction of phenol with formaldehyde. It has several uses such as in radio, electrical insulators, and telephone casings. When we used Bakelite as a substrate material, there was no resonance on the lower band. But, resonance was found at $14.40 \mathrm{GHz}$ center frequency

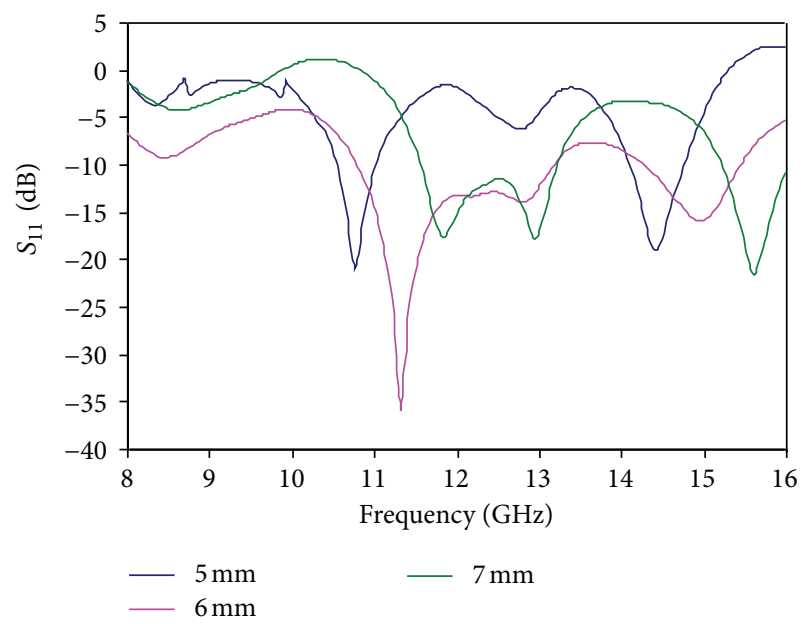

FIGURE 5: Reflection coefficient with different values of radius, $R$.

on the upper band where $-10 \mathrm{~dB}$ bandwidth is $1.68 \mathrm{GHz}$ $(14.64 \mathrm{GHz}-13.96 \mathrm{GHz})$.

Aluminum is a silvery soft, white ductile material. Aluminium is extensively used in transportation, aerospace industry, and structural materials. It has low density and ability to resist corrosion for which it is popular. When we used aluminum as a substrate material, there was no resonance on the lower band. But, resonance was found at $14.32 \mathrm{GHz}$ centre frequency on the upper band where $-10 \mathrm{~dB}$ bandwidth is $1.44 \mathrm{GHz}(15.04 \mathrm{GHz}-13.60 \mathrm{GHz})$.

Finally, FR4 has been used in the proposed design as substrate material. One resonance was achieved at $11.32 \mathrm{GHz}$ center frequency on the lower band and another resonance at 14.96 GHz on the upper band. The dielectric properties of the materials have been listed in Table 1 .

A parametric study has been done to observe the effects of the proposed antenna parameters. Mainly, the effects of the different parameters on the return loss have been observed.

Figure 5 shows the reflection coefficient for different values of $R$. It includes $L=40 \mathrm{~mm}, W=40 \mathrm{~mm}, S_{1}=10 \mathrm{~mm}$, $S_{2}=16.5 \mathrm{~mm}, S_{3}=12 \mathrm{~mm}, W_{1}=4 \mathrm{~mm}, W_{2}=7 \mathrm{~mm}$, $L_{g}=40 \mathrm{~mm}, W_{g}=40, W_{3}=18 \mathrm{~mm}, W_{4}=6 \mathrm{~mm}$, $W_{5}=8 \mathrm{~mm}, W_{6} \stackrel{g}{=} 4 \mathrm{~mm}$, and $W_{7}=7 \mathrm{~mm}$ with $R$. It was 


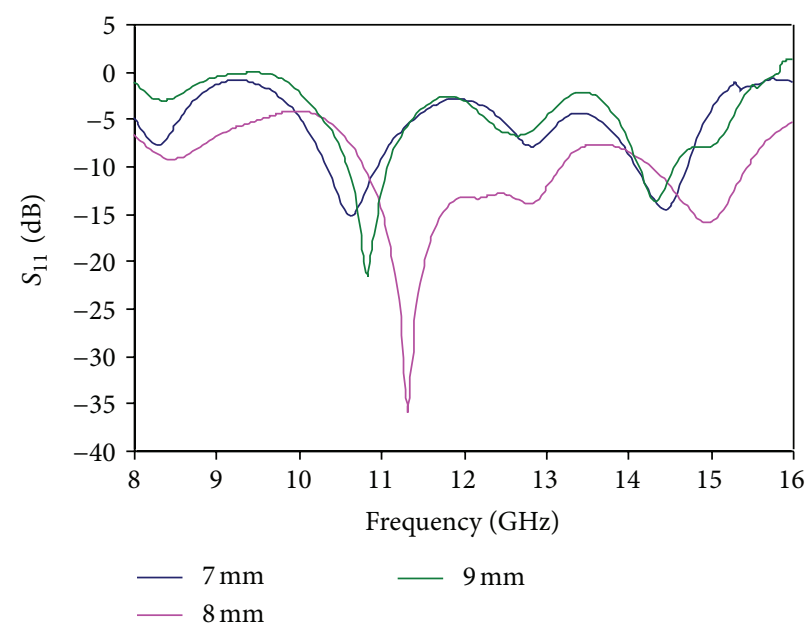

FIGURE 6: Reflection coefficient with different values of $W_{5}$.

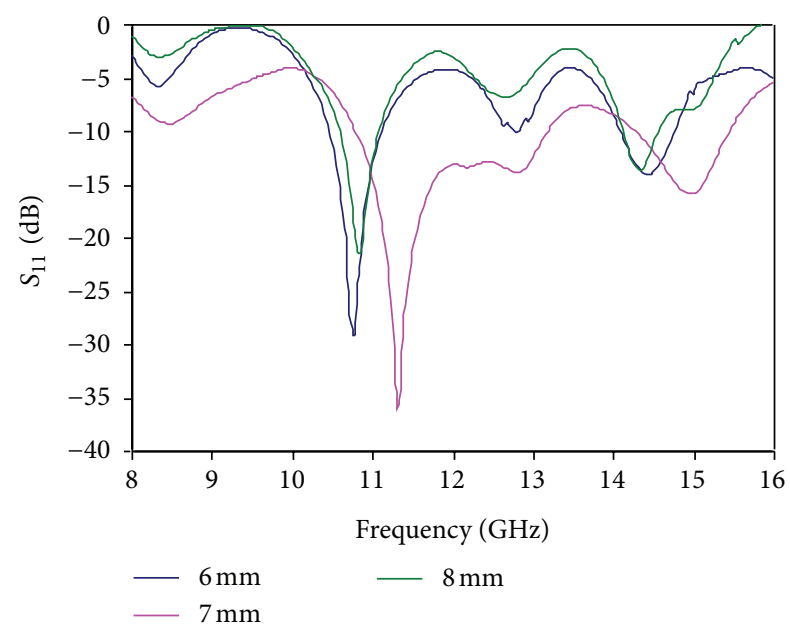

Figure 7: Reflection coefficient with different values of $W_{7}$.

TABLE 1: Dielectric properties of substrate materials.

\begin{tabular}{lccc}
\hline Material & Permittivity & Permeability & Loss tangent \\
\hline Aluminum & 1 & 1.000021 & 0 \\
Teflon (tm) & 2.1 & 1 & 0.001 \\
Duroid (tm) & 2.2 & 1 & 0.0009 \\
Bakelite & 4.8 & 1 & 0.002 \\
FR4 (proposed) & 4.6 & 1 & 0.02 \\
\hline
\end{tabular}

shown that resonances were shifted on both of the lower and upper bands using the value of radius as $5 \mathrm{~mm}$ and $7 \mathrm{~mm}$.

By using $R=6 \mathrm{~mm}$, desired dual band has been obtained with improved bandwidth on both of the lower and upper bands. That is why the optimized value of radius $R$ is $6 \mathrm{~mm}$.

The reflection coefficient for different values of $W_{5}$ is as shown in Figure 6. It includes $L=40 \mathrm{~mm}, W=40 \mathrm{~mm}, R=$ $6 \mathrm{~mm}, S_{1}=10 \mathrm{~mm}, S_{2}=16.5 \mathrm{~mm}, S_{3}=12 \mathrm{~mm}, W_{1}=4 \mathrm{~mm}$, $W_{2}=7 \mathrm{~mm}, L_{g}=40 \mathrm{~mm}, W_{g}=40, W_{3}=18 \mathrm{~mm}, W_{4}=$ $6 \mathrm{~mm}, W_{6}=4 \mathrm{~mm}$, and $W_{7}=7 \mathrm{~mm}$ with $W_{5}$. It was seen

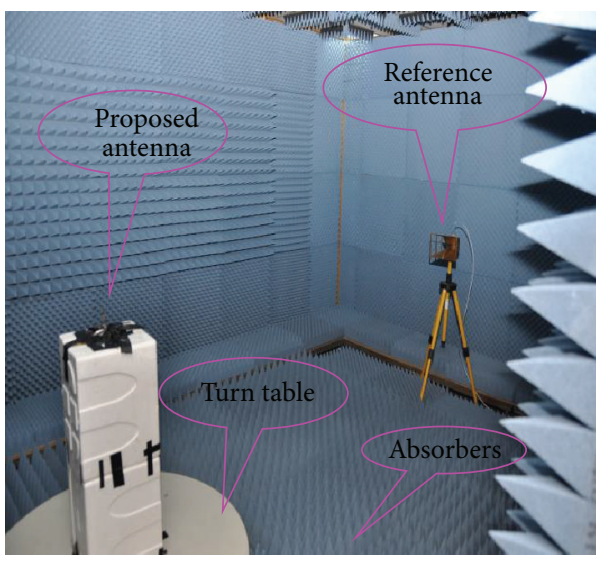

FIGURE 8: The photograph of anechoic chamber for prototype measurement.

from the graph clearly that better coupling has been acquired at the upper band using the value of $W_{5}$ as $8 \mathrm{~mm}$. That is why the optimized value is $8 \mathrm{~mm}$.

Figure 7 shows the reflection coefficient for different values of $W_{7}$. It includes $L=40 \mathrm{~mm}, W=40 \mathrm{~mm}, R=6 \mathrm{~mm}$, $S_{1}=10 \mathrm{~mm}, S_{2}=16.5 \mathrm{~mm}, S_{3}=12 \mathrm{~mm}, W_{1}=4 \mathrm{~mm}, W_{2}=$ $7 \mathrm{~mm}, L_{g}=40 \mathrm{~mm}, W_{g}=40, W_{3}=18 \mathrm{~mm}, W_{4}=6 \mathrm{~mm}$, $W_{5}=8 \mathrm{~mm}$, and $W_{6}=4 \mathrm{~mm}$ with $W_{7}$. It was observed that the width of the microstrip line has greater significance to the coupling at the entire frequency bands. The coupling can be achieved when $W_{7}$ is $7 \mathrm{~mm}$.

\section{Results and Discussion}

The anechoic chamber used in this study which was conducted by the microwave laboratory, at the Institute of Space Science (ANGKASA), UKM, Malaysia, had been illustrated in Figure 8. The dimensions of this anechoic chamber are $5.5 \times 4.5 \times 3.5 \mathrm{~m}^{3}$. A reference antenna, a horn antenna, was used in this analysis that was double ridge guided. 


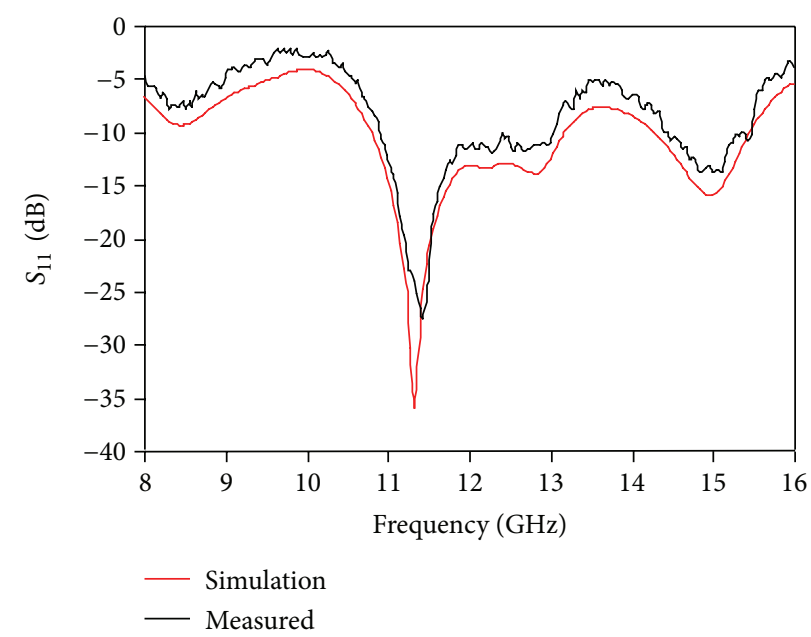

FIGURE 9: Comparisons between simulated and measured return loss on FR4 material.

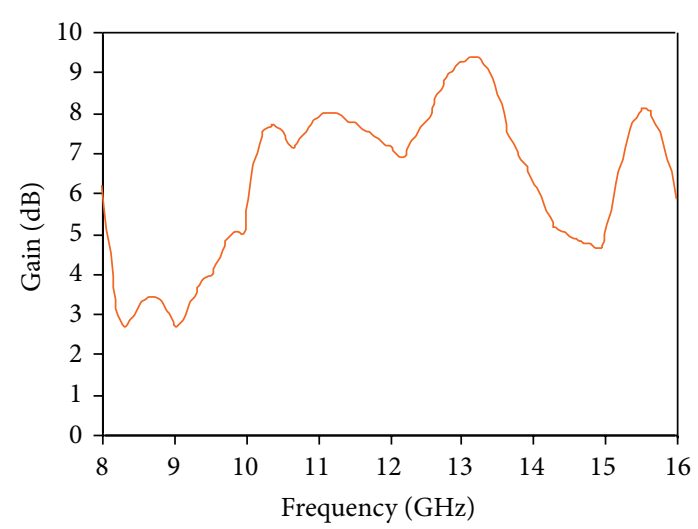

FIGURE 10: Gain of the proposed antenna.

Pyramidal shaped absorbers have been used on the walls, ceiling, and floor with less than $-60 \mathrm{~dB}$ reflectivity. The diameter of the turntable is $1.2 \mathrm{~m}$. A vector network analyzer (VNA) (model number: Agilent E8362C) has been used for the measurements with a range of up to $20 \mathrm{GHz}$. In this way, the prototype of the $\Omega$ shaped proposed antenna has been measured in a standard far-field testing environment.

The return loss with measurement and simulation of the proposed microstrip antenna has been demonstrated in Figure 9. The $-10 \mathrm{~dB}$ bandwidths of $2.12 \mathrm{GHz}$ from $10.92 \mathrm{GHz}$ to $13.04 \mathrm{GHz}$ and $1.08 \mathrm{GHz}$ from $14.40 \mathrm{GHz}$ to $15.48 \mathrm{GHz}$ have been achieved from the measurements which show that at the lower band the resonance shifted from $11.32 \mathrm{GHz}$ to $11.44 \mathrm{GHz}$ and the bandwidth slightly decreased. Moreover, at the upper band the resonant frequency shifted from $14.96 \mathrm{GHz}$ to $14.84 \mathrm{GHz}$ and the bandwidth decreased from $1.16 \mathrm{GHz}$ to $1.08 \mathrm{GHz}$, while the return loss value decreased at resonance frequency.

Gain of the proposed antenna has been shown in Figure 10. Figure 10 has illustrated that $7.82 \mathrm{dBi}$ achieved at the first resonance for $11.44 \mathrm{GHz}$ and $5.66 \mathrm{dBi}$ at the second resonance $14.84 \mathrm{GHz}$. In addition, the gain for the upper band

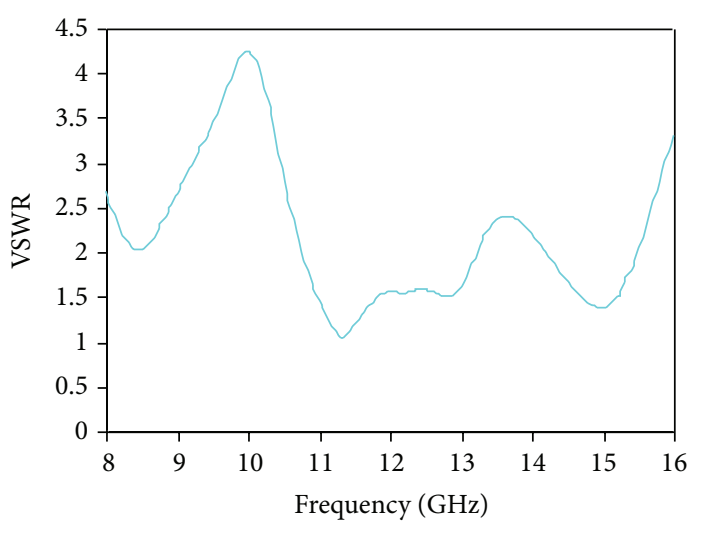

FIGURE 11: VSWR of the proposed antenna.

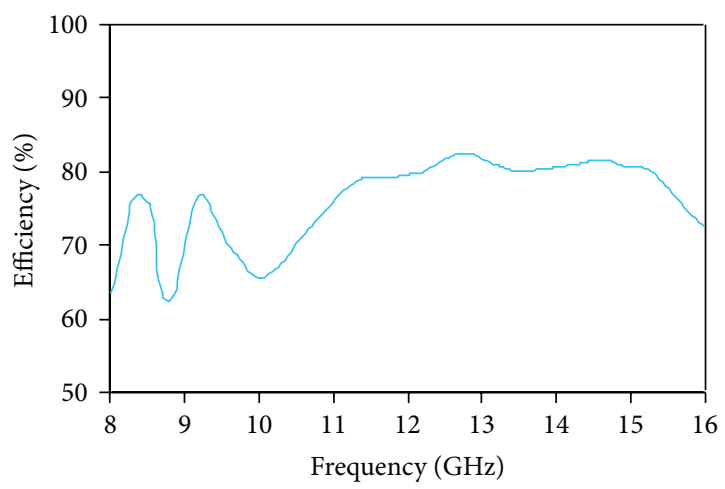

FIGURE 12: Radiation efficiency of the proposed antenna.

is less than that for the lower band. Figure 11 shows VSWR of the proposed antenna. The value of VSWR is less than 2 that is found from the graph apparently. It is a desired value. Figure 12 has shown the radiation efficiency of the proposed antenna. In Figure 11, the average lower band efficiency is $79.76 \%$ whereas $80.36 \%$ is the higher band efficiency. It 


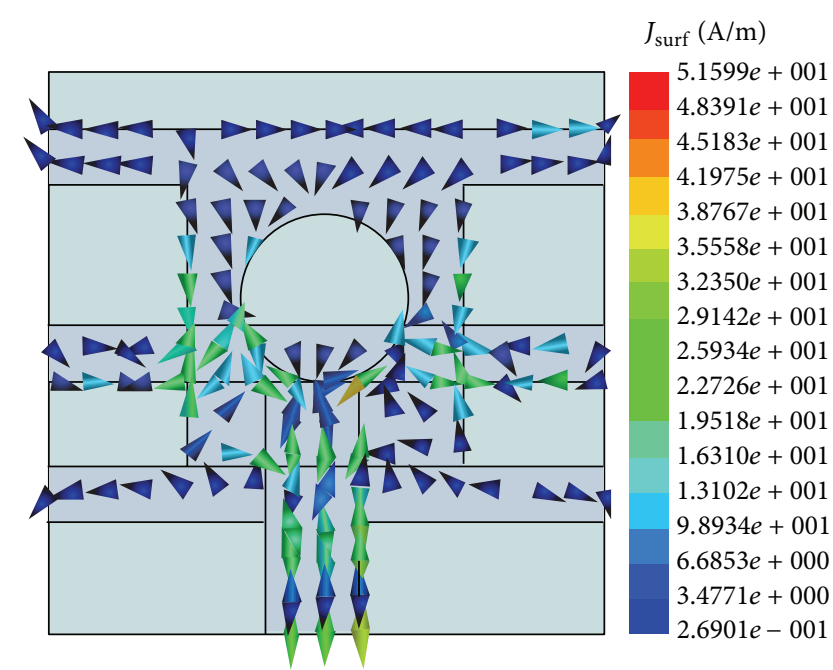

(a)

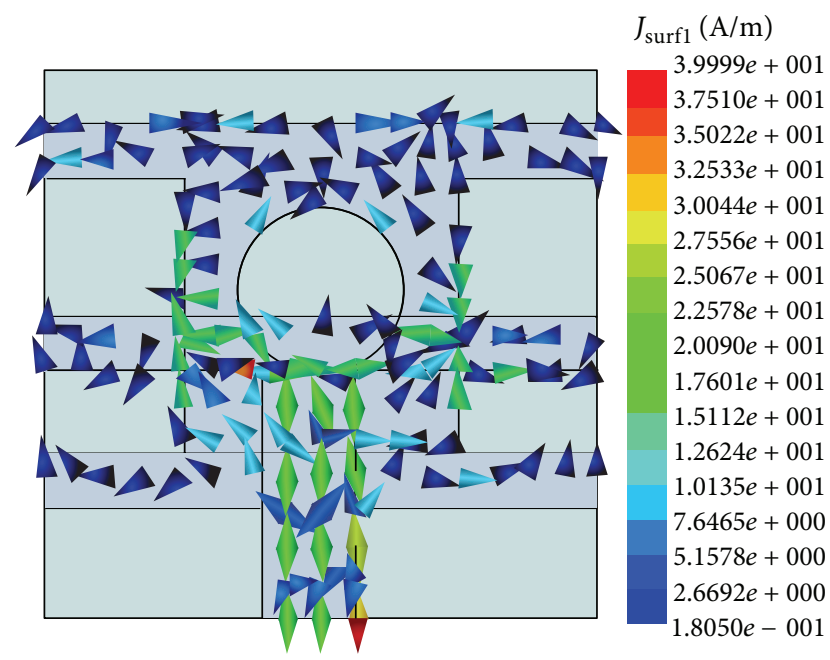

(b)

Figure 13: Current distribution at (a) $11.32 \mathrm{GHz}$ and (b) $14.96 \mathrm{GHz}$.

can also be observed that lower band radiation efficiency is smaller than the higher band one.

Figure 13 has been shown the current distribution of the proposed antenna for (a) $11.32 \mathrm{GHz}$ and (b) $14.96 \mathrm{GHz}$. It can be seen that a large amount of current flows at feeding line. Electric field has been created much in this point. Current distribution is more stable in lower band than in upper band. The creation of electric field near slots is reasonable. As a result, excitation is strong in the entire parts of the antenna on both the lower band and the upper band.

The radiation pattern of the proposed antenna with measurement has been demonstrated in Figure 14 for (a) 11.32 GHz at E-plane, (b) $11.32 \mathrm{GHz}$ at $\mathrm{H}$-plane, (c) $14.96 \mathrm{GHz}$ at E-plane, and (d) $14.96 \mathrm{GHz}$ at $\mathrm{H}$-plane. The $\mathrm{E} \varphi$ and $\mathrm{E}_{\theta}$ fields indicate the cross-polar and copolar components, respectively. The effect of cross-polarization in radiation pattern is lowermicrostrip antenna. The cross-polarization effect is higher in the $\mathrm{H}$-plane for both resonances. When frequency increases, the effect increases interpreting from the radiation pattern simply. Moreover, almost omnidirectional and symmetrical radiation patterns have been attained along both E-plane and H-plane.

It has been observed that the same radiation pattern exists over the $\mathrm{X}$ - and $\mathrm{Ku}$-bands. The obtained radiation patterns denote that the proposed antenna delivers linear polarization where the level of cross-polarization is lower than that of copolarization in all of the simulated radiation patterns. When the radiation pattern of a microstrip antenna is symmetric and omnidirectional, it faces some reasonable benefits. One is that resonance would never be shifted at different directions and a large amount of stable power would be at the direction of broadside beam. Another advantage is that the radiation pattern would be more durable on the operational bands.

The phase variation of the proposed antenna is plotted in Figure 15. It is realized from the graph that the proposed
TABLE 2: Comparisons between existing and proposed antennas.

\begin{tabular}{lccc}
\hline Author & Bandwidth $(\mathrm{MHz})$ & Gain $(\mathrm{dBi})$ & Dimension $(\mathrm{mm} \times \mathrm{mm})$ \\
\hline Proposed & 2120,1080 & $7.82,5.66$ & $40 \times 40$ \\
{$[18]$} & 220,650 & $7.6,4.1$ & $20 \times 14$ \\
{$[19]$} & 45,20 & $1.45,1.1$ & $100 \times 100$ \\
\hline
\end{tabular}

antenna has the phase variation that is linear across both the upper and the lower operating frequency bands. This phase variation indicates that all the frequency components of the signal have the same pulse distortion due to the same propagation delay. Comparisons between existing and proposed antennas have been tabulated in Table 2 .

The Smith chart of the proposed antenna is shown in Figure 16. Two resonances $\mathrm{m} 1$ and $\mathrm{m} 2$ are identified clearly from this chart which has validated the evidences.

\section{Conclusion}

A $40 \mathrm{~mm} \times 40 \mathrm{~mm}$ double inverted F-shape patch antenna has been discussed in this paper for dual band-operation. The measured impedance bandwidths ( $2: 1 \mathrm{VSWR}) 2.12 \mathrm{GHz}$ on the upper band and $1.08 \mathrm{GHz}$ on the lower band with average gains of $7.82 \mathrm{dBi}$ and $5.66 \mathrm{dBi}$ have been achieved belonging to radiation efficiency $79.76 \%$ and $80.36 \%$. Since the antenna layout is simple and straightforward, fabrication and measurement are comparatively easier. The generalized design procedure for the proposed antenna for dual frequency operation has also been improved than conventional. It is realized that a good combination has been focused between measurements and simulations that validate our proposed double F-shaped design concept. The patch resonator, 


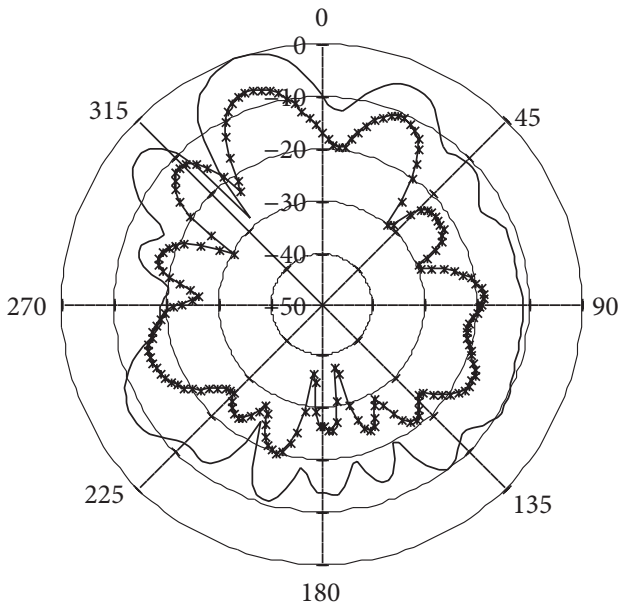

(a)

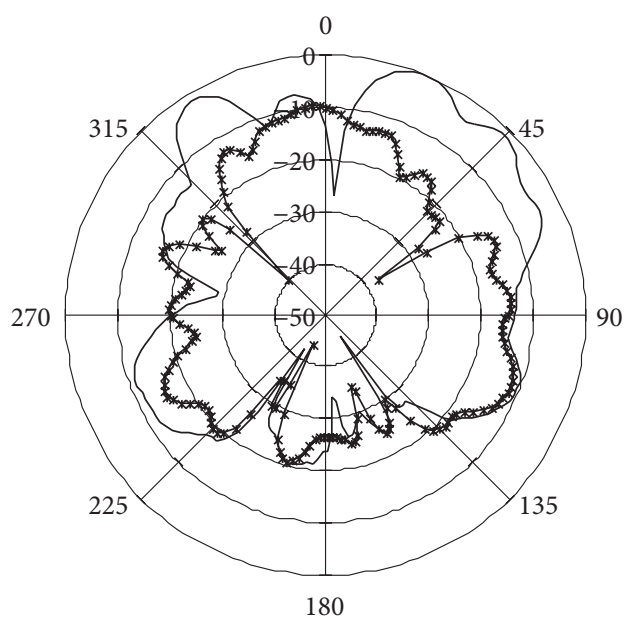

Copolarization

Cross-polarization

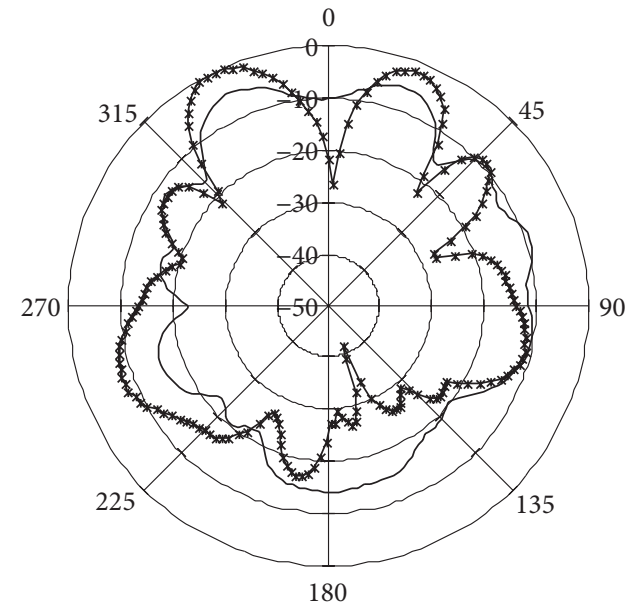

(b)

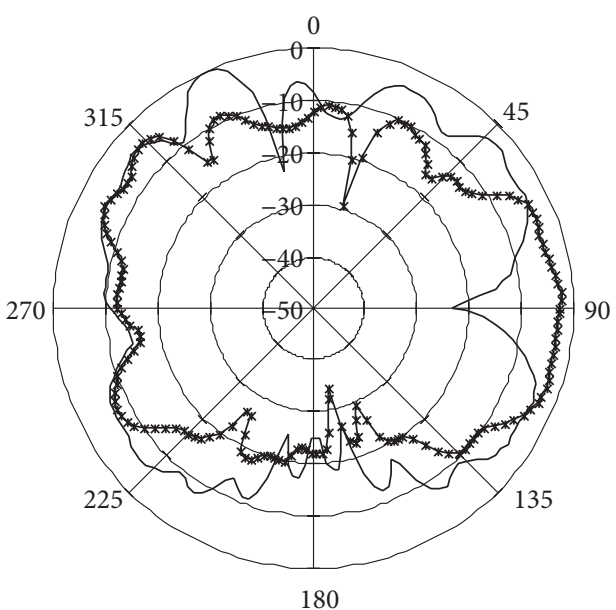

- Copolarization

* Cross-polarization

(d)

Figure 14: Radiation patterns of the proposed antenna, (a) $11.32 \mathrm{GHz}$ at E-plane, (b) 11.32 at H-plane, (c) $14.96 \mathrm{GHz}$ at E-plane, and (d) $14.96 \mathrm{GHz}$ at $\mathrm{H}$-plane.

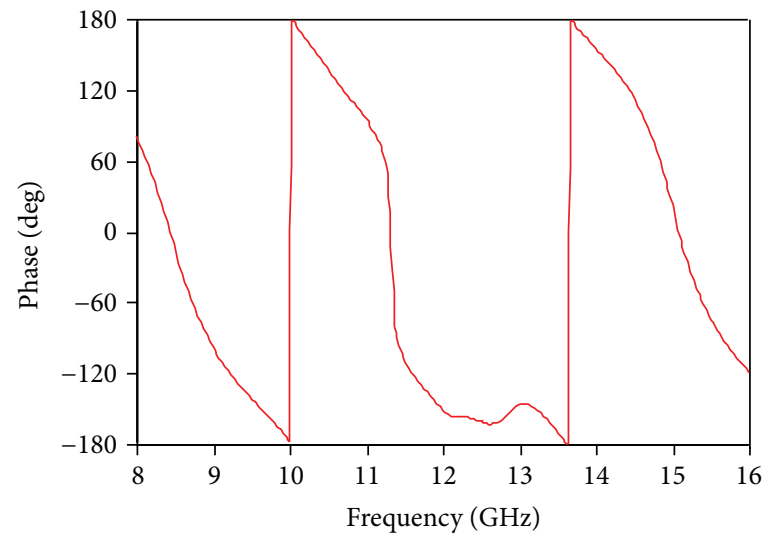

FIGURE 15: Phase value of the proposed antenna. 


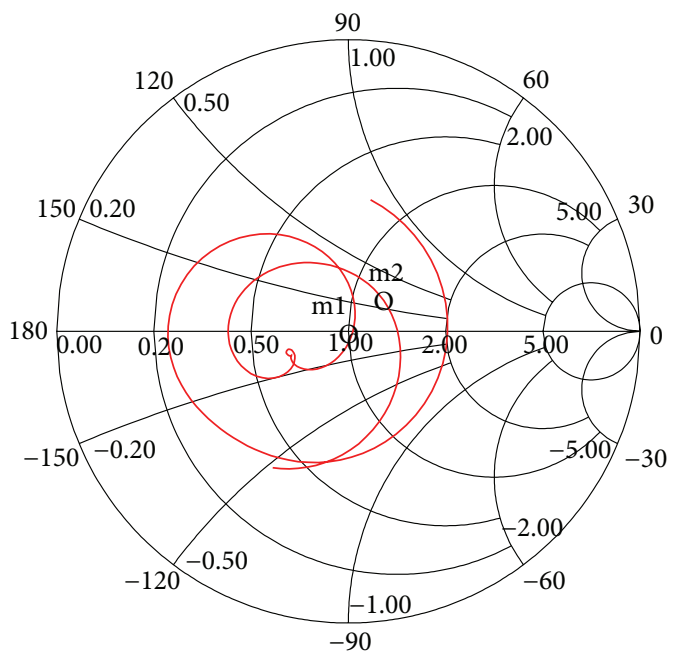

\begin{tabular}{|l|l|l|l|l|}
\hline Name & Freq. & Ang. & Mag. & RX \\
\hline $\mathrm{m} 1$ & 11.3200 & 3.3645 & 0.0156 & $1.0317+0.0019 i$ \\
\hline $\mathrm{m} 2$ & 14.9600 & 31.4364 & 0.1589 & $1.2926+0.2198 i$ \\
\hline
\end{tabular}

FIGURE 16: Smith chart of the proposed antenna.

compact size, stable radiation patterns, low cross polarization, efficiency with improved bandwidth, and higher gain have made the proposed double F-shaped antenna compatible for X-band and Ku-band applications.

\section{Conflict of Interests}

The authors declare that there is no conflict of interests regarding the publication of this paper.

\section{References}

[1] Y.-C. Lu and Y.-C. Lin, "A mode-based design method for dualband and self-diplexing antennas using double T-stubs loaded aperture," IEEE Transactions on Antennas and Propagation, vol. 60, no. 12, pp. 5596-5603, 2012.

[2] M. R. I. Faruque, M. T. Islam, and N. Misran, "Evaluation of specific absorption rate (SAR) reduction for PIFA antenna using metamaterials," Frequenz, vol. 64, no. 7-8, pp. 144-149, 2010.

[3] J.-S. Row and S.-W. Wu, "Circularly-polarized wide slot antenna loaded with a parasitic patch," IEEE Transactions on Antennas and Propagation, vol. 56, no. 9, pp. 2826-2832, 2008.

[4] C.-C. Yu and X.-C. Lin, "A wideband single chip inductorloaded CPW-fed inductive slot antenna," IEEE Transactions on Antennas and Propagation, vol. 56, no. 5, pp. 1498-1501, 2008.

[5] S. I. Latif, L. Shafai, and S. K. Sharma, "Bandwidth enhancement and size reduction of microstrip slot antennas," IEEE Transactions on Antennas and Propagation, vol. 53, no. 3, pp. 994-1003, 2005.

[6] W. S. T. Rowe and R. B. Waterhouse, "Investigation of proximity coupled patch antennas suitable for MMIC integration," in IEEE Antennas and Propagation Society Symposium Digest, pp. 15911594, June 2004.
[7] S.-C. Gao, L.-W. Li, T.-S. Yeo, and M.-S. Leong, "FDTD analysis of a slot-loaded meandered rectangular patch antenna for dualfrequency operation," IEE Proceedings: Microwaves, Antennas and Propagation, vol. 148, no. 1, pp. 65-71, 2001.

[8] J.-W. Wu, H.-M. Hsiao, J.-H. Lu, and S.-H. Chang, "Dual broadband design of rectangular slot antenna for 2.4 and $5 \mathrm{GHz}$ wireless communication," Electronics Letters, vol. 40, no. 23, pp. 1461-1463, 2004.

[9] C.-M. Su, H.-T. Chen, and K.-L. Wong, "Printed dual-band dipole antenna with U-slotted arms for $2.4 / 5.2 \mathrm{GHz}$ WLAN operation," Electronics Letters, vol. 38, no. 22, pp. 1308-1309, 2002.

[10] Y.-H. Suh and K. Chang, "Low cost microstrip-fed dual frequency printed dipole antenna for wireless communications," Electronics Letters, vol. 36, no. 14, pp. 1177-1179, 2000.

[11] D. Nashaat, H. A. Elsadek, and H. Ghali, "Dual-band reduced size PIFA antenna with U-slot for Bluetooth and WLAN applications," in Proceedings of the IEEE Antennas and Propagation Society International symposium, vol. 2, pp. 962-967, Columbus, Ohio, USA, June 2003.

[12] C.-C. Lin, G.-Y. Lee, and K.-L. Wong, "Surface-mount dualloop antenna for $2.4 / 5 \mathrm{GHz}$ WLAN operation," Electronics Letters, vol. 39, no. 18, pp. 1302-1304, 2003.

[13] Y.-L. Kuo and K.-L. Wong, "Printed double-T monopole antenna for $2.4 / 5.2 \mathrm{GHz}$ dual band WLAN operations," IEEE Transactions on Antennas and Propagation, vol. 51, no. 9, pp. 2187-2192, 2003.

[14] R. Azim, M. T. Islam, and N. Misran, "Dual polarized microstrip patch antenna for Ku-band application," Informacije MIDEM, vol. 41, no. 2, pp. 114-117, 2011.

[15] L. Liu, S. W. Cheung, R. Azim, and M. T. Islam, "A compact circular-ring antenna for ultra-wideband applications," Microwave and Optical Technology Letters, vol. 53, no. 10, pp. 2283-2288, 2011.

[16] R. Azim, M. T. Islam, and N. Misran, "A planar monopole antenna for UWB applications," International Review of Electrical Engineering, vol. 5, no. 4, pp. 1848-1852, 2010.

[17] M. M. Islam, M. T. Islam, and M. R. I. Faruque, "Dual-band operation of a microstrip patch antenna on a Duroid 5870 substrate for Ku- and K-bands," The Scientific World Journal, vol. 2013, Article ID 378420, 10 pages, 2013.

[18] M. H. Ullah, M. T. Islam, J. S. Mandeep, and N. Misran, "A new double L-shaped multiband patch antenna on a polymer resin material substrate," Applied Physics A, vol. 110, no. 1, pp. 199-205, 2013.

[19] W.-T. Hsieh, T.-H. Chang, and J.-F. Kiang, "Dual-band circularly polarized cavity-backed annular slot antenna for GPS receiver," IEEE Transactions on Antennas and Propagation, vol. 60, no. 4, pp. 2076-2080, 2012. 

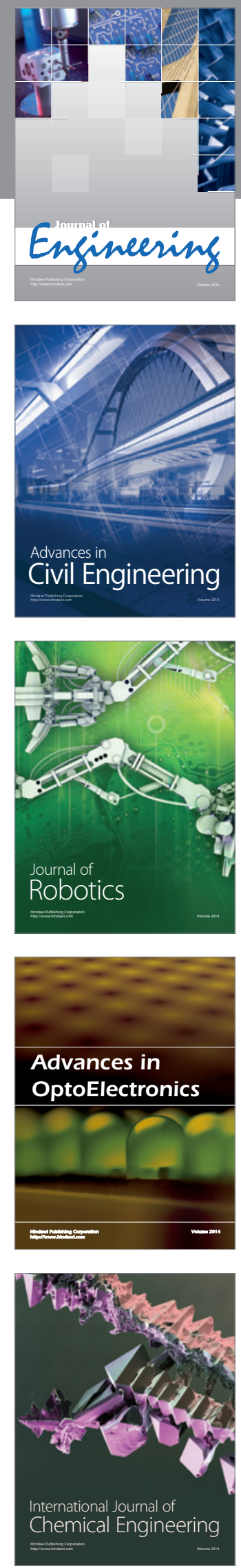

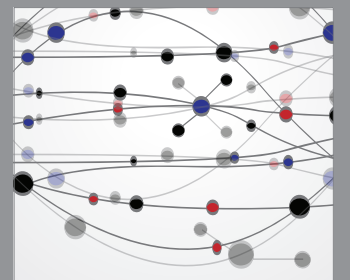

The Scientific World Journal
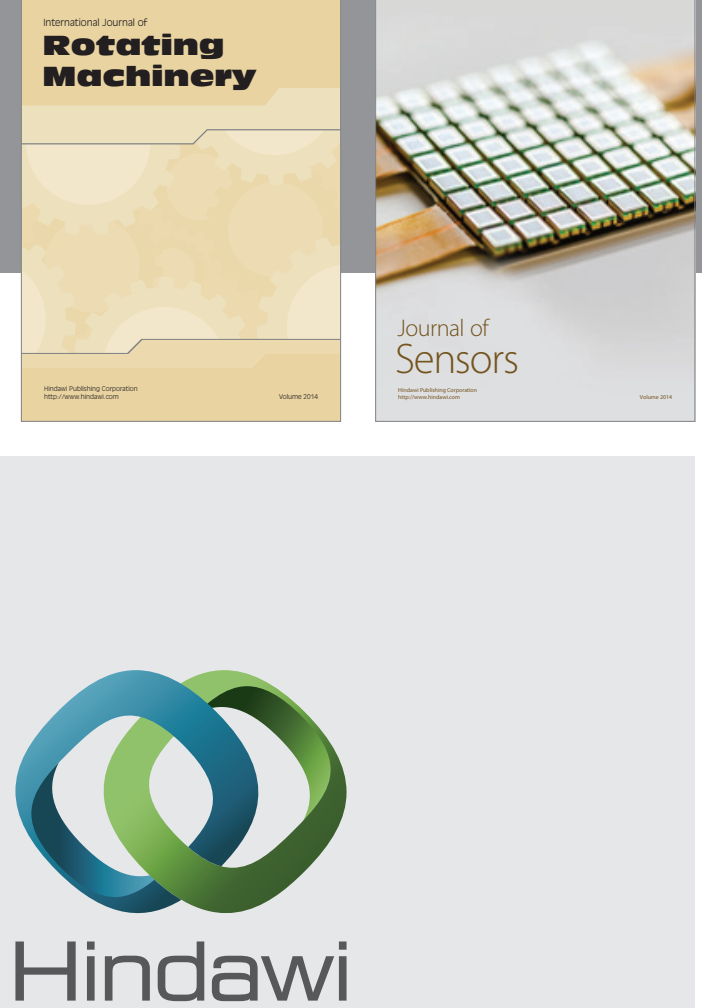

Submit your manuscripts at http://www.hindawi.com
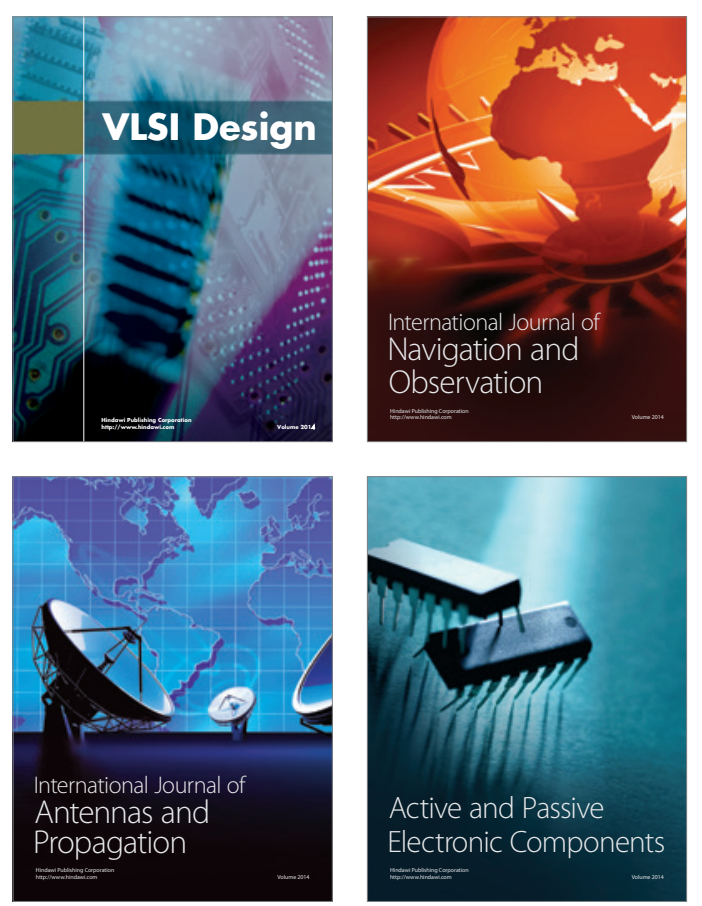
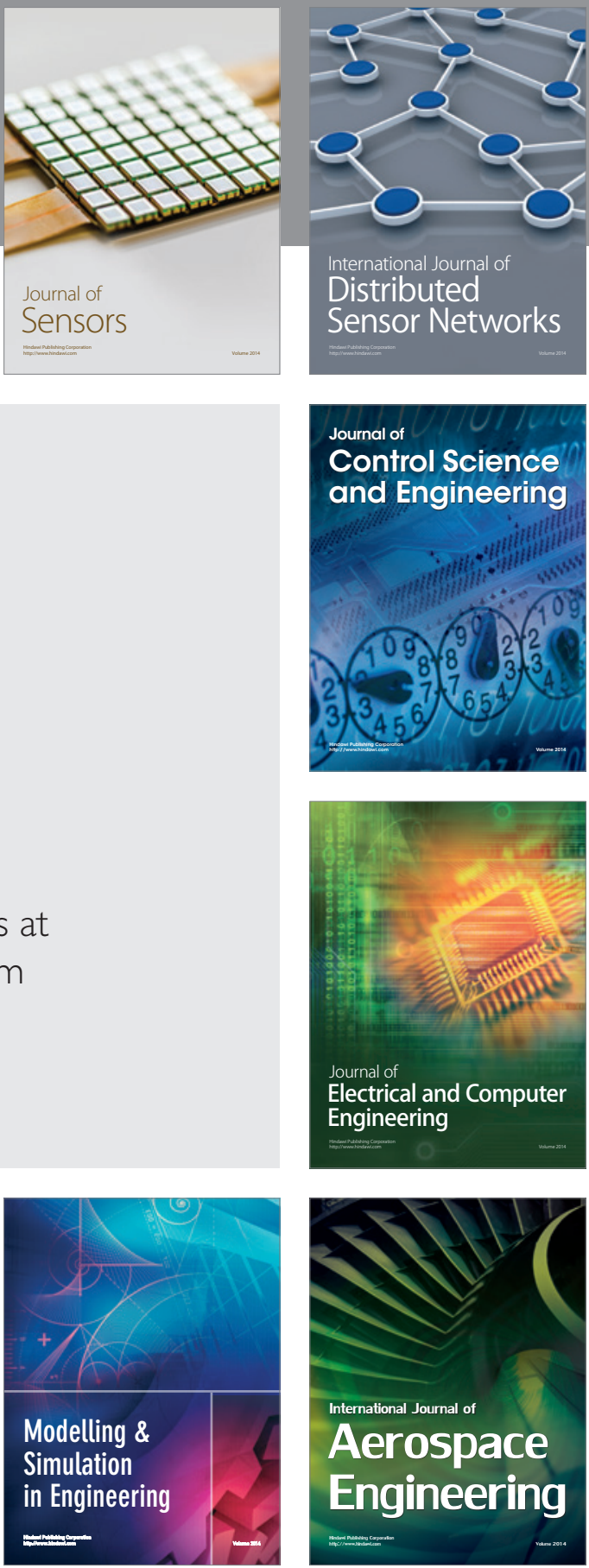

Journal of

Control Science

and Engineering
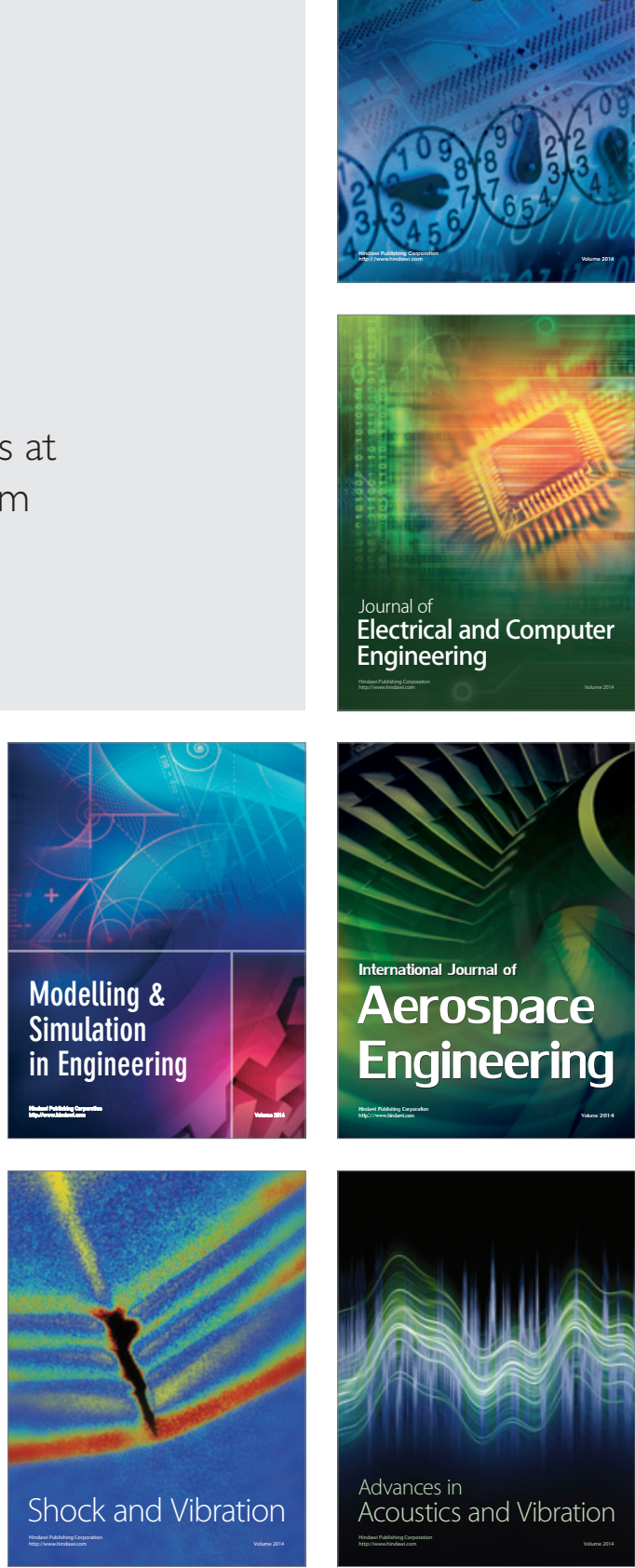